\title{
Unsettling intimacies: Re-cognizing ecological relations with the work of Jean Clandinin
}

\author{
Alexandra Olsvik \\ Department of Secondary Education, University of Alberta
}

\begin{abstract}
For Jean Clandinin, narrative inquiry is not about being but becoming and as such posits knowledge as a continuous, non-teleological process rather than a static object. Experiential knowledge, for Clandinin, then, is intimately bound up with the vicissitudes of lived experience. If stories make meaning from experience, they open up an imaginative space through which researchers can come to understand experience as well as the knowledge that emerges from it or re-cognize such. Inquiring into experiential knowledge through narratives is valuable for research, and particularly for research that engages ecological crises, because it enables a more robust, nuanced view of life-both human and nonhuman-to emerge. Further, as Clandinin's work reconfigures the role of the researcher, it unsettles hierarchical assumptions within the research space, allowing for collaboration, polyphonic texts, and reconfigured understandings to emerge. Clandinin's work troubles dominant narratives about knowledge that presuppose conceptual reification and mastery. As such, narrative inquiry has the potential to support research that is interested in reconfiguring relationships between human and non-human "nature" in ways that do not necessarily fit into dominant narratives about knowledge in education. Using a framework informed by contemporary eco-criticism and trauma theory, I consider how narrative inquiry might offer reparative methods for educational research that engages ecological crises. As narrative inquiry aims to honour the particularity of experience and promote growth without assimilating plurality into an objective singularity, its methods have the capacity to provide insights into ecological relations that are critical, selfreflexive, and ethically responsive.
\end{abstract}

Keywords: narrative inquiry, ecology, Clandinin, curriculum studies.

Cite as: Olsvik A. 2021. Unsettling intimacies: Re-cognizing ecological relations with the work of Jean Clandinin. Alberta Academic Review, Vol 4 (1): 10, EEGSA-SEGSA Special Issue: Remote Connections, DOI: 10.29173/aar130 